\title{
Barrel-shaped design of the forearm free flap for lower lip reconstruction: a pilot case-control study
}

\author{
Nan-Chin Lin ${ }^{1,2+}$, Shih-Lung $\operatorname{Lin}^{3+}$ and Kuo-Yang Tsai ${ }^{2,4^{*}}$ (D)
}

\begin{abstract}
Background: Radial free forearm flaps is indicated patients with total or near-total defects in their lower lip. The purpose of our study was to evaluate a simple and effective barrel-shaped design of the radial free forearm flap for lower lip reconstruction and to compare its clinical outcomes with those of a conventional rectangular shaped free forearm flap.

Methods: Twenty-two patients with a lower lip carcinoma who underwent radial forearm free flap reconstructive surgery were enrolled in this study between January 1, 2012, and December 31, 2017. A barrel-shaped design of radial forearm free flap for reconstruction was used in 8 patients (case group), and a rectangular design was used in 14 patients (control group). The patients' quality of life was evaluated preoperatively and postoperatively in all the patients using the European Organization for Research and Treatment of Cancer Quality of Life (EORTC-HN35) questionnaire. We analyzed the differences in the EORTC QLQ-HN35 scores pre- and postoperatively between the case and control group.
\end{abstract}

Results: The patients in the case group had better outcomes in swallowing, speech, social eating, social contact, and dry mouth than the control group at 1-year follow-up $(P<0.05)$.

Conclusions: The use of a barrel-shaped design free forearm flap for lower lip reconstruction is an effective procedure and can achieve better results than the use of rectangular free forearm flap.

Keywords: Lower lip reconstruction, Forearm free flap, Quality of life, Lip defect surgery, Lower lip carcinoma surgery

\section{Background}

Complex lower lip defects can pose formidable challenges during reconstructive surgery after tumor excision, burn injury debridement, or facial trauma. Moreover, speech problems, oral incontinence, and poor cosmetic outcomes usually result from the loss of

\footnotetext{
* Correspondence: 72837@cch.org.tw

${ }^{+}$Nan-Chin Lin and Shih-Lung Lin contributed equally to this work.

${ }^{2}$ Department of Oral and Maxillofacial surgery, Changhua Christian Hospital,

No. 235, Xuguang Rd., Changhua City, Changhua County 500, Taiwan

${ }^{4}$ College of Nursing and Health Science, Da-Yeh University, Changhua, Taiwan

Full list of author information is available at the end of the article
}

sensation in the lower lip and continuity with the orbicularis muscle of the lower lip. Small defects in the lower lip can be reconstructed using local flaps to obtain favorable functional and cosmetic outcomes. Several reconstruction methods have been reported for cases in which a defect in the lower lip exceeds two-thirds of the total lip volume, however, to the best of our knowledge, there is no simple procedure to achieve both competence of the oral cavity as well as aesthetic outcomes [1].

Full-thickness defects exceeding half of the lower lip volume cannot be closed with the remaining lip tissue without causing microstomia; however, reconstruction

(c) The Author(s). 2020 Open Access This article is licensed under a Creative Commons Attribution 4.0 International License, which permits use, sharing, adaptation, distribution and reproduction in any medium or format, as long as you give appropriate credit to the original author(s) and the source, provide a link to the Creative Commons licence, and indicate if changes were made. The images or other third party material in this article are included in the article's Creative Commons licence, unless indicated otherwise in a credit line to the material. If material is not included in the article's Creative Commons licence and your intended use is not permitted by statutory regulation or exceeds the permitted use, you will need to obtain permission directly from the copyright holder. To view a copy of this licence, visit http://creativecommons.org/licenses/by/4.0/ The Creative Commons Public Domain Dedication waiver (http://creativecommons.org/publicdomain/zero/1.0/) applies to the data made available in this article, unless otherwise stated in a credit line to the data. 
with local tissue can sometimes achieve good lower lip continuity. In cases of total or near-total defects in the lower lip, Sakai et al. (1989) have indicated the use of radial forearm free flaps in reconstructive surgery. The use of free flaps can provide distant and healthy tissues that are taken away from head and neck region; however, frequent drooling occurs owing to the lack of sensation in the flap and discontinuity of the orbicularis muscle [2].

To reconstruct a dynamic sphincter, several methods of suspension procedures using the tendo-fasciocutaneous flap have been described in the literature [3]. The method first described by Sakai et al. [2] has been used and modified by other researchers [4-6].. However, this type of reconstructive procedure has disadvantages, including sagging in the middle portion of the flap, particularly when the patients are eating or drinking which in turn causes drooling $[4,5]$. Studies have also reported that approximately $15 \%$ of patients have no palmaris longus which is the most used muscle for suspension procedures $[7,8]$.

Drooling is an unacceptable social problem for patients. Thus, the purpose of our study was to evaluate a simple (without suspension) and effective (different shape) design of a free forearm flap for lower lip reconstruction and to further compare it with a conventional rectangular free forearm flap.

\section{Methods}

\section{Patients}

This case-control study was approved by the Institutional Review Board and Ethical Committee of Changhua Christian Hospital. All participants provided written informed consent regarding the publication of their images. The study identified 25 patients with lower lip carcinoma who underwent radial forearm free flap reconstructive surgery between January 1, 2012, and December 31, 2017. Patients who were lost to follow-up $(n=2)$ and who had a tumor in the corner of the mouth $(n=1)$ were excluded. Finally, 22 patients were included in the analysis. The barrel-shaped design of the radial forearm free flap for reconstruction was used in 8 patients (case group) and the rectangular design was used in the remaining 14 patients (control group).

\section{Evaluation of quality of life}

The patients' quality of life was evaluated preoperatively (t1 in the case group and $\mathrm{t}^{\prime}$ ' in the control group) and postoperatively (1-year follow-up, t 2 in the case group and $\mathrm{t}^{\prime}$ ' in the control group) using the European Organization for Research and Treatment of Cancer Quality of Life questionnaire (EORTC QLQ-HN35) [9]. The detailed EORTC QLQ-HN35 and manual book are shown in Supplementary File 1 and Supplementary File 2. The EORTC QLQ-HN35 questionnaire is a 35-item module comprising 7 symptom scales (pain, swallowing, taste or smell, speech, social eating, social contacts, and sexuality) and 6 symptom items (teeth problems, trismus, dry mouth, sticky saliva, cough, and feeling ill) $[10,11]$. The patients were instructed to rate the presence of a symptom or limitation of a function using the Likert-like four-point scale (not at all, a little, quite a bit, or very much). Five questions from the EORTC QLQ-HN35 questionnaire were answered with a yes or no [12]. The internal consistency of the included domains was adequate [13]. In addition, the EORTC QLQ-HN35 questionnaire is less susceptible to changes in the clinical status of the patients compared with other measurement tools [13]. In this study, the scores were transformed into 0-100 scale scores with a high score indicating a high level of symptoms or dysfunctions. Both these instruments have formally validated Taiwanese translations (Supplementary File 3) [14]. We analyzed the change in the EORTC QLQ-HN35 scores (t2-t1 score and t2'-t1' score) between the case and control groups.

\section{Barrel-shaped design of the radial forearm free flap}

The present study introduces an effective design for large lower lip defect reconstruction using a free forearm flap without a tendon sling. First, the flap was designed in a barrel-like shape and folded along the direction of the pedicle to reconstruct both the mucosal lining and external skin (Fig. 1). This design resulted in a convex shape in the middle portion of the flap after folding. Second, if the horizontal defect was $\mathrm{X} \mathrm{cm}$, we harvested the flap with a longitudinal dimension of $\mathrm{X}-1 \mathrm{~cm}$ (Fig. 1a and c). If the vertical defect, including the outer skin and inner mucosa, was $\mathrm{Y}$ $\mathrm{cm}$, we harvested the flap with a transverse dimension of $\mathrm{Y}+2 \mathrm{~cm}$ (Fig. $1 \mathrm{~b}$ and $\mathrm{c}$ ). Shortening the horizontal length can maintain some tension and prevent forward sagging of the flap. The vertical height of the flap must be lengthened because firstly, when the flap is plicated, its thickness will consume some skin length and secondly, to make the center of the flap higher, and similar to a normal lip and to prevent sagging of the middle portion of the flap.

In the control group, a rectangular shaped flap was harvested and the size was matched with that of the defect. For example, if the horizontal defect was $\mathrm{X} \mathrm{cm}$ and the vertical defect, including the outer skin and inner mucosa, was $\mathrm{Y} \mathrm{cm}$, we harvested an $\mathrm{X} \times \mathrm{Y} \mathrm{cm}$ flap.

\section{Statistical analysis}

Continuous variables are presented as mean \pm standard deviation and categorical variables as percentages. The Mann-Whitney's U-test was used to compare continuous variables between the case and control groups. A Pvalue of $<0.05$ was considered statistically significant. All statistical analyses were performed using the Statistical Package for the Social Sciences software for Windows (version 16, SPSS, Chicago, Il, USA). 


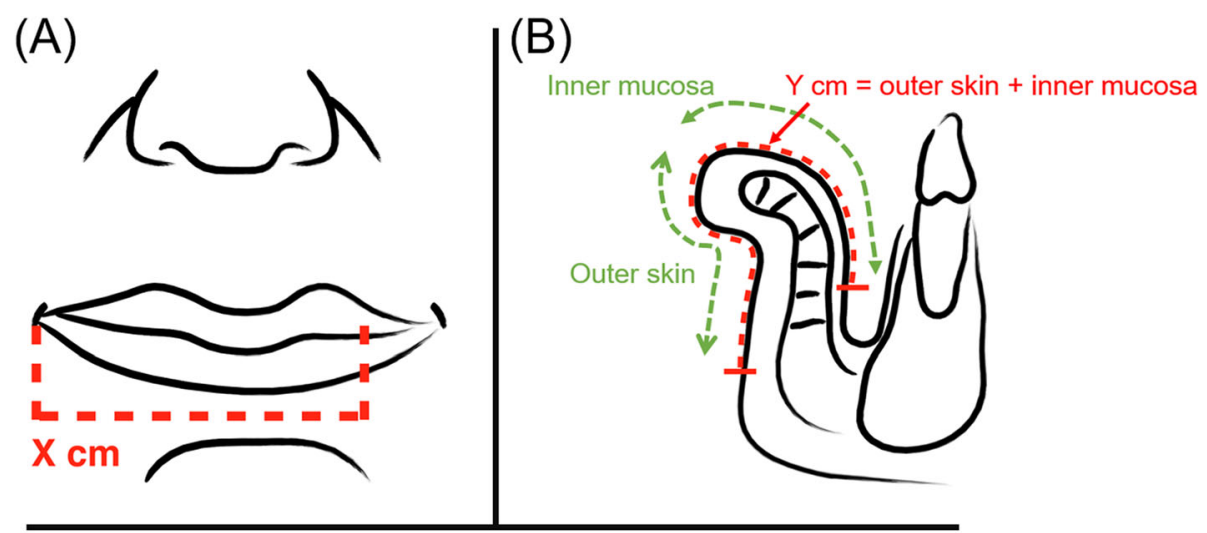

(C)

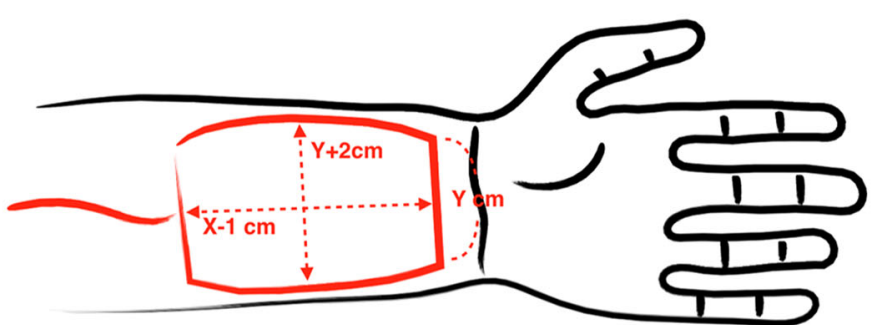

Fig. 1 Illustrates the barrel-shaped design of the radial forearm free flap. (a) If the horizontal defect was " $X$ " $\mathrm{cm}$ and (b) the vertical defect from the outer skin to the inner mucosa surface was " $Y$ " $\mathrm{cm}$. (c) The flap was harvested with a longitudinal dimension of $X-1 \mathrm{~cm}$ and with a transverse dimension of $Y+2 \mathrm{~cm}$ in a barrel-like shape

\section{Results}

In our clinical case, the horizontal defect was $7 \mathrm{~cm}$ and the vertical defect was $4 \mathrm{~cm}$ (including the outer skin and inner mucosa), respectively (Fig. 2a). Therefore, the free forearm flap was designed in a barrel-like shape with dimensions of $6 \times 6 \mathrm{~cm}$ (Fig. 2b). The postoperative and 1year follow-up images of the patient are shown in Fig. 3. The patient was eating a normal diet and had good oral competence by the second-year of follow-up (Fig. 4).

The patient characteristics of both groups are summarized in Table 1. The characteristics, including age, sex, body mass index, postoperative radiotherapy, tumor staging, defect size, alcohol consumption, smoking, and history of betel nut chewing, did not differ between the two groups. All the flaps were harvested and transferred without any complications. No case of donor site infection or wound dehiscence was observed.

The patients were evaluated preoperatively and postoperatively at the 1 -year follow-up. Table 2 summarizes the results of the analyses of both the groups. Patients in the case group had better outcomes in swallowing, speech, social eating, social contact, and dry mouth than the control group $(P<0.05)$, whereas no significant differences were identified for pain, sense, sexuality, teeth, open mouth, sticky saliva, cough, pain killer, nutritional supplements, feeding tube, and gain or loss of weight.

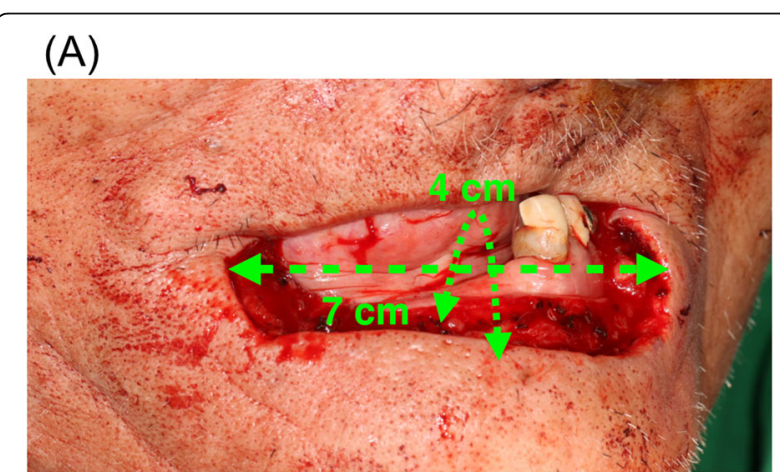

(B)

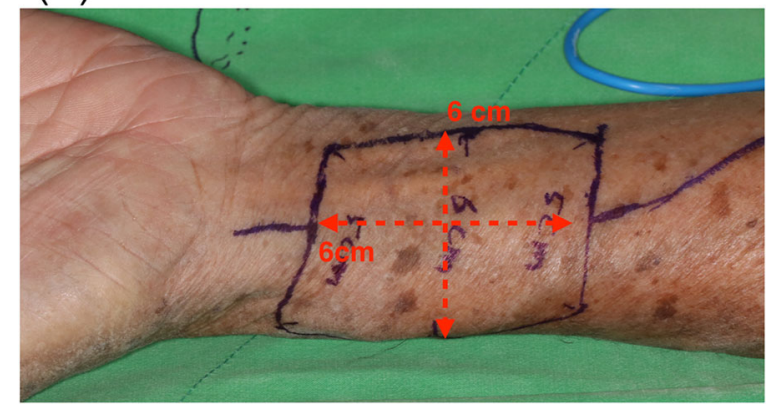

Fig. 2 In the clinical case, a the horizontal defect was $7 \mathrm{~cm}$ and the vertical defect from the outer skin to the inner mucosa surface was $4 \mathrm{~cm}$. $\mathbf{b}$ The free forearm flap was harvested in a barrel-like shape with a dimension of $6 \times 6 \mathrm{~cm}$ 


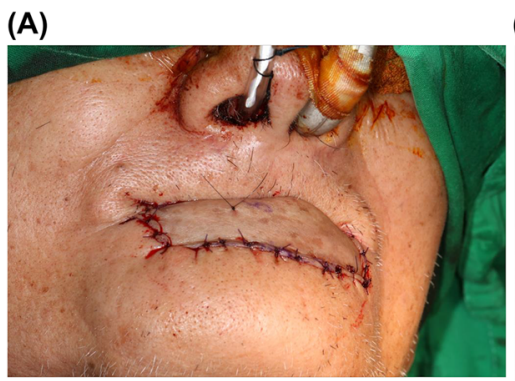

(B)

(C)
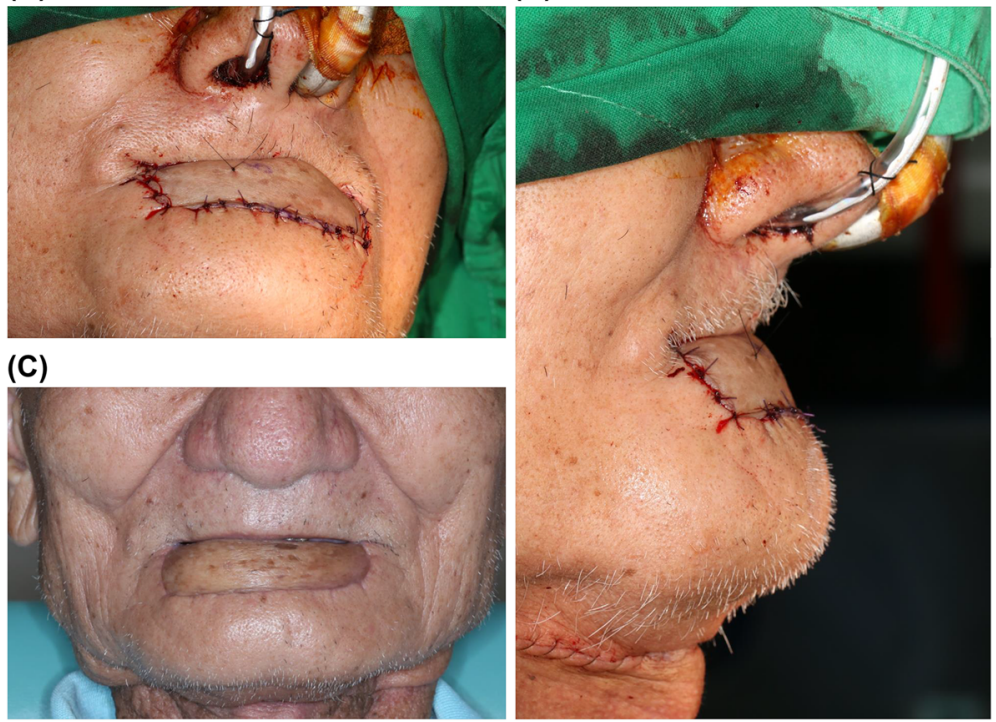

Fig. 3 In the postoperative frontal view (a) and lateral view (b), the middle portion of the flap will be slightly convex to restore the oral competence. At the same time, shortening the longitudinal length of the harvested flap can maintain some tension to prevent sagging of the flap. (c) The image at the 1-year follow-up still shows a very good result in the frontal view

\section{Discussion}

The importance of the lips as an anatomical structures goes beyond its vital functions and includes eating, drinking, phonation, speaking, and expressing emotions. In cases of lip carcinoma, reconstruction of the lower lip often requires a complex surgical approach to best achieve the goal of restoring oral competence and maintaining an adequate oral aperture to facilitate oral hygiene [15]. In the present study, the barrel-shaped design used to reconstruct the lower lip defect achieved better outcomes in swallowing, speech, social eating, social contact, and dry mouth than the rectangular free

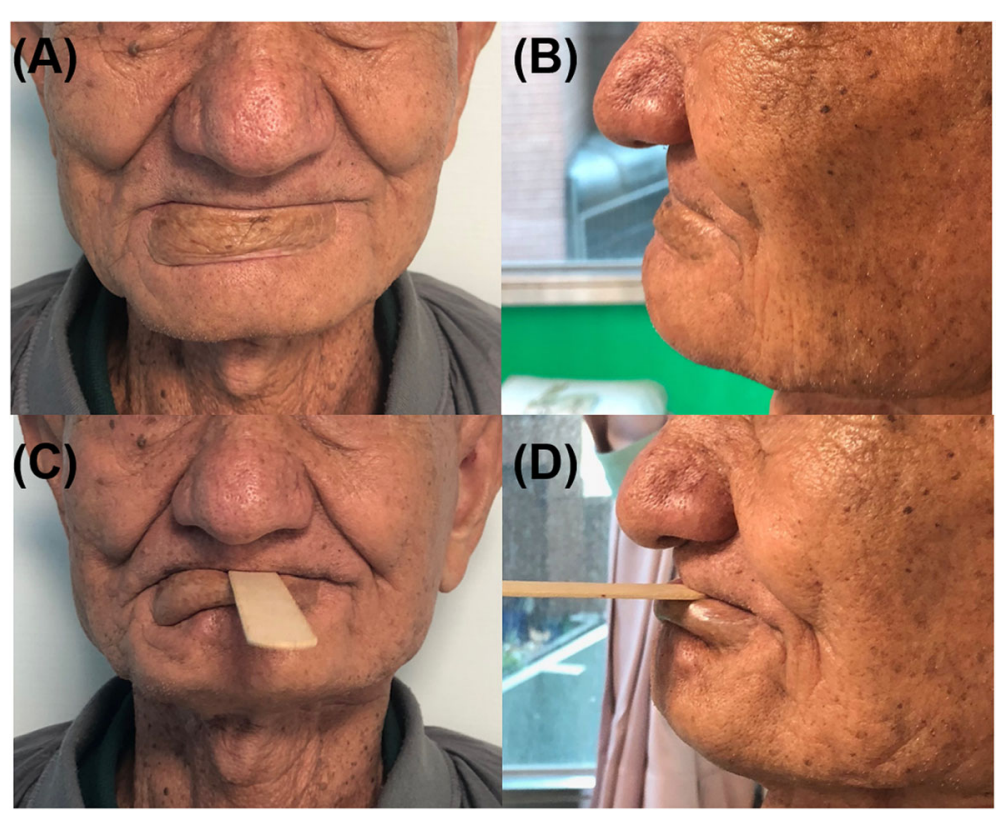

Fig. 4 The image at the 2-year follow-up, the frontal view (a) and lateral view (b) show good oral competence after surgery. In the lip functional test, (c) and (d) show that the patient can use his lip to hold the stick showing that the barrel-shaped design of radial forearm free flap can restore oral competence 
Table 1 Clinical characteristics of both groups

\begin{tabular}{|c|c|c|}
\hline & $\begin{array}{l}\text { Case } \\
\boldsymbol{n}=8(\%)\end{array}$ & $\begin{array}{l}\text { Control } \\
\boldsymbol{n}=14(\%) \\
\end{array}$ \\
\hline Age (years), mean & $61.25 \pm 8.44$ & $57.86 \pm 6.03$ \\
\hline Sex: Male & $8(100.0)$ & $10(90.9)$ \\
\hline Female & $0(0)$ & $1(9.1)$ \\
\hline Body mass index & $22.84 \pm 3.52$ & $24.57 \pm 4.73$ \\
\hline Postoperative radiotherapy & $0(0)$ & $1(9.1)$ \\
\hline T status: $\mathrm{T1}$ & $4(50.0)$ & $10(71.4)$ \\
\hline $\mathrm{T} 2$ & $4(50.0)$ & $2(14.3)$ \\
\hline T3 & $0(0)$ & $2(14.3)$ \\
\hline N status: NO & $8(100.0)$ & $14(100.0)$ \\
\hline M status: M0 & $8(100.0)$ & $14(100.0)$ \\
\hline Defect size: More than or equal to $7 \times 7 \mathrm{~cm}$ & $1(12.5)$ & $3(21.4)$ \\
\hline $6 \times 6 \mathrm{~cm}$ to $7 \times 7 \mathrm{~cm}$ & $5(62.5)$ & $7(50.0)$ \\
\hline Smaller than $6 \times 6 \mathrm{~cm}$ & $2(25.0)$ & $4(28.6)$ \\
\hline Alcohol consumption: Yes & $4(50.0)$ & $10(71.4)$ \\
\hline No & $4(50.0)$ & $4(28.6)$ \\
\hline Smoking: Yes & $8(100.0)$ & $12(85.7)$ \\
\hline No & $0(0)$ & $2(14.3)$ \\
\hline Betel nut chewing: Yes & $8(100.0)$ & $14(100.0)$ \\
\hline No & $0(0)$ & $0(0)$ \\
\hline
\end{tabular}

forearm flap. The barrel-shaped free forearm flap can achieve good oral competence and enable patients to return to a normal diet with one-stage reconstructive surgery without any additional suspension procedures.

Drooling is an unacceptable problem that not only affects eating, drinking, and swallowing but also results in social problems [5]. It is well-known that achieving oral competence is the key to the prevention of drooling. In the present study, we also evaluated drooling using the EORTC QLQ-HN35 scores in the "Swallowing" and "Social eating" sections. In the "Swallowing" section, there were three of four questions about drooling including "Have you had a problem eating liquids, pureed food, or solid food?" In the "Social eating" section, there were four questions for patients about drooling including "Have you had trouble eating or enjoying meals?" and "Have you had trouble eating in front of your family or in front of other people?" In the case group, the increased scores in the "Swallowing" and "Social eating" sections were significantly lower than those of the control group. We can reasonably presume that the oral competence of in the case group was better than that of the control group. This key point resulted in better functions of swallowing, speaking, and social contact (Table 2). However, when intra-group comparisons were performed, we observed that the EORTC QLQ-HN35 scores for both control and case groups were getting worse in function and social problem pre-operation to post-operation. However, more cases and data must be collected to approve this finding in the future. To reconstruct a dynamic sphincter, several suspension procedures using the free forearm flap have been reported in the literature [2-6]. Sakai et al. [2] described the use of the palmaris longus tendon with a free forearm flap for full-thickness defects of the lower lip. The tendon was fixed to the orbicularis oris muscle and epidermis of the nasolabial area; however, the suspension procedure could not maintain oral competence while the patients were eating or speaking [5]. Jeng et al. modified the method described by Sakai et al. [5]. They harvested the free forearm flap according to the defect size without any modification as well as harvested the palmaris longus tendon which is sutured to the remaining orbicularis muscle and the angles of the mouth. However, the use of the suspension procedure for reconstruction has well-known disadvantages. First, approximately $15 \%$ of patients have no palmaris longus which is the most commonly used muscle for suspension procedures $[7,8]$. Second, the procedure has a longer operation time. Finally, the middle portion of the suspended flap sags. In comparison, the barrel-shaped design of the free forearm flap, when folded, is slightly convex in the middle portion of the flap. This can help in achieving oral competence, as shown in our clinical case. The use of a barrelshaped free forearm flap does not result in a longer operating time. 
Table 2 EORTC QOL-HN 35 scores were evaluated preoperatively (t1 in case group and t1' in control group) and post-operatively (1year follow up, $\mathrm{t} 2$ in case group and t2' in control group). Mean (standard deviation), Median (interquartile range) and $p$ values (Mann-Whitney $U$ test) of the change in EORTC QOL-HN 35 scores over time between $\mathrm{t} 1$ and $\mathrm{t} 2$, and between $\mathrm{t} 1^{\prime}$ and $\mathrm{t} 2^{\prime}$

\begin{tabular}{|c|c|c|c|c|c|c|c|c|c|}
\hline \multirow{3}{*}{$\begin{array}{l}\text { Changes in EORTC } \\
\text { QOL-HN } 35 \\
\text { score }\end{array}$} & \multicolumn{8}{|c|}{ EORTC QOL-HN 35 scores } & \multirow{3}{*}{$\begin{array}{l}p- \\
\text { value }\end{array}$} \\
\hline & \multicolumn{4}{|c|}{ Case, $n=8$} & \multicolumn{4}{|c|}{ Control, $n=14$} & \\
\hline & $\begin{array}{l}\mathrm{t} 1 \\
\text { (Mean) }\end{array}$ & $\begin{array}{l}\mathrm{t} 2 \\
\text { (Mean) }\end{array}$ & t2-t1 (Mean) & $\overline{\mathrm{t} 2-\mathrm{t} 1 \text { (Median) }}$ & $\begin{array}{l}\mathrm{t} 1^{\prime} \\
\text { (Mean) }\end{array}$ & $\begin{array}{l}\mathrm{t} 2^{\prime} \\
\text { (Mean) }\end{array}$ & $\mathrm{t} 2^{\prime}-\mathrm{t} 1^{\prime}$ (Mean) & $\mathrm{t} 2^{\prime}-\mathrm{t1}^{\prime}$ (Median) & \\
\hline Pain & 31.250 & 34.375 & $3.125 \pm 5.786$ & $0(0-6.250)$ & 33.750 & 32.857 & $\begin{array}{l}-0.893 \pm \\
3.144^{\mathrm{a}}\end{array}$ & $0(-6.250-0)$ & 0.1251 \\
\hline Swallowing & 25.0 & 28.125 & $3.125 \pm 3.341$ & $3.125(0-6.250)$ & 31.25 & 60.714 & $\begin{array}{l}29.464 \pm \\
14.998\end{array}$ & $\begin{array}{l}25.0(18.750- \\
43.750)\end{array}$ & 0.0001 \\
\hline Sense & 25.0 & 28.125 & $3.125 \pm 5.786$ & $0(0-6.250)$ & 25.0 & 35.714 & $\begin{array}{l}10.714 \pm \\
22.391\end{array}$ & $0(0-12.50)$ & 0.7409 \\
\hline Speech & 25.0 & 29.167 & $4.167 \pm 4.454$ & $4.167(0-8.333)$ & 26.189 & 52.379 & $\begin{array}{l}26.190 \pm \\
24.646\end{array}$ & $25.0(8.333-4.167)$ & 0.0119 \\
\hline Social eating & 28.125 & 43.750 & $\begin{array}{l}15.625 \pm \\
13.774\end{array}$ & $\begin{array}{l}9.375(6.25- \\
25.0)\end{array}$ & 30.357 & 60.714 & $\begin{array}{l}30.357 \pm \\
14.052\end{array}$ & $25.0(18.750-50.0)$ & 0.0197 \\
\hline Social contact & 25.0 & 43.750 & $18.75 \pm 4.432$ & $\begin{array}{l}17.50(15.0- \\
22.5)\end{array}$ & 25.0 & 52.571 & $27.571 \pm 9.982$ & $25.0(20.0-35.0)$ & 0.039 \\
\hline Sexuality & 25.0 & 31.250 & $6.250 \pm 11.573$ & $0(0-12.5)$ & 25.0 & 35.714 & $\begin{array}{l}10.714 \pm \\
18.898\end{array}$ & $0(0-25.0)$ & 0.7409 \\
\hline Teeth & 31.250 & 37.50 & $6.250 \pm 11.573$ & $0(0-12.5)$ & 39.286 & 46.429 & $7.143 \pm 11.720$ & $0(0-25.0)$ & 0.8678 \\
\hline Open mouth & 37.50 & 37.50 & 0 & 0 & 39.286 & 50.0 & $\begin{array}{l}10.714 \pm \\
18.898\end{array}$ & $0(0-25.0)$ & 0.1370 \\
\hline Dry mouth & 31.250 & 43.750 & $12.50 \pm 13.363$ & $12.50(0-25.0)$ & 28.571 & 57.142 & $28.571 \pm 9.078$ & $25.0(25.0-25.0)$ & 0.0082 \\
\hline Sticky saliva & 25.0 & 25.750 & $0.750 \pm 0.886$ & $0.50(0-1.50)$ & 25.0 & 39.286 & $\begin{array}{l}14.286 \pm \\
12.839\end{array}$ & $25.0(0-25.0)$ & 0.1503 \\
\hline Cough & 25.0 & 25.0 & 0 & 0 & 25.0 & 28.571 & $3.571 \pm 9.078$ & 0 & 0.3603 \\
\hline $\begin{array}{l}\text { Questionnaire 31- } \\
35 \\
\text { summed up }\end{array}$ & 50.0 & 52.5 & $2.50 \pm 3.273$ & $1.25(0-5.0)$ & 51.429 & 51.429 & 0 & 0 & 0.1094 \\
\hline
\end{tabular}

The present study has several limitations. First, the small sample size might have prevented the identification of significant differences between the case and control groups. Second, its retrospective design might have increased the risk of bias in case selection. Finally, we did not compare the outcomes between the barrelshaped design of the free forearm flap and a procedure involving suspension. Therefore, further studies are warranted to determine this.

\section{Conclusion}

In conclusion, we demonstrate that a barrel-shaped design free forearm flap for lower lip reconstruction achieves better outcomes than a rectangular design for function and social contact evaluated by an EORTC QLQ-HN35 questionnaire. We found that the use of this barrel-shaped forearm free flap for lower lip reconstruction is an effective procedure, which can improve oral competence and prevent drooling.

\section{Supplementary information}

Supplementary information accompanies this paper at https://doi.org/10. 1186/s12893-020-00792-x.

Additional file 1 : Supplementary File 1. European Organization for Research and Treatment of Cancer Quality of Life questionnaire (EORTC QLQ-HN35) in English version.

Additional file $\mathbf{2}$ : Supplementary File 2. Manual book of EORTC QLQ-HN35 questionnaire.

Additional file 3 : Supplementary File 3. EORTC QLQ-HN35 questionnaire in Taiwanese version.

Abbreviations

EORTC QLQ-HN35: European Organization of Research and Treatment of Cancer Quality of Life head and neck 35 questionnaire.

\section{Acknowledgments}

The authors would like to thank Enago (www.enago.com) for the English language review.

\section{Authors' contributions}

$\mathrm{NCL}$ and SLL participated in manuscript preparation include conception. $\mathrm{NCL}$ and KYT participated in data collection and/or processing. NCL and SLL 
participated in drafting the article. KYT participated in critically revising the article. All authors read and approved the final manuscript.

\section{Funding}

None.

\section{Availability of data and materials}

The datasets used and analyzed during the current study are available from the corresponding author on reasonable request.

\section{Ethics approval and consent to participate}

This study was approved by the Institutional Review Board and Ethical Committee of Changhua Christian Hospital. IRB number 190421. All participants provided written informed consent to participate in the study.

\section{Consent for publication}

Written informed consent was obtained from the patient for publication of clinical data including images that may be identifiable.

\section{Competing interests}

The authors declare that they have no competing interests.

\section{Author details}

${ }^{1}$ School of Dentistry, China Medical University, Taichung, Taiwan.

${ }^{2}$ Department of Oral and Maxillofacial surgery, Changhua Christian Hospital, No. 235, Xuguang Rd., Changhua City, Changhua County 500, Taiwan. ${ }^{3}$ Department of Plastic and Reconstructive Surgery, Changhua Christian Hospital, Changhua, Taiwan. ${ }^{4}$ College of Nursing and Health Science, Da-Yeh University, Changhua, Taiwan.

Received: 3 March 2020 Accepted: 9 June 2020

Published online: 12 June 2020

\section{References}

1. Karapandzic M. Reconstruction of lip defects by local arterial flaps. Br J Plast Surg. 1974;27:93-7.

2. Sakai S, Soeda S, Endo T, Ishii M, Uchiumi E. A compound radial artery forearm flap for the reconstruction of lip and chin defects. Br J Plast Surg. 1989;42:337-8.

3. Silberstein E, Krieger $Y$, Shoham Y, Arnon O, Sagi A, Bogdanov-Berezovsky A. Total lip reconstruction with tendinofasciocutaneous radial forearm flap. ScientificWorldJournal. 2014;2014:219728. https://doi.org/10.1155/2014/ 219728.

4. Sadove RC, Luce EA, McGrath PC. Reconstruction of the lower lip and chin with the composite radial forearmpalmaris longus free flap. Plast Reconstr Surg. 1991;88:209-14.

5. Jeng SF, Kuo YR, Wei FC, Su CY, Chien CY. Total lower lip reconstruction with a composite radial forearmpalmaris longus tendon flap: a clinical series. Plast Reconstr Surg. 2004;113:19-23.

6. Lee JW, Jang YC, Oh SJ. Esthetic and functional reconstruction for burn deformities of the lower lip and chin with free radial forearm flap. Ann Plast Surg. 2006;56:384-6.

7. Agarwal P. Absence of the palmaris longus tendon in Indian population. Indian J Orthop. 2010;44:212-5.

8. Ndou R, Gangata H, Mitchell B, Ngcongo T, Louw G. The frequency of absence of palmaris longus in a south African population of mixed race. Clin Anat. 2010;23:437-42.

9. Bjordal K, Ahlner-Elmqvist M, Tollesson E, Jensen AB, Razavi D, Maher EJ, Kaasa S. Development of a European Organization for Research and Treatment of Cancer (EORTC) questionnaire module to be used in quality of life assessments in head and neck cancer patients. EORTC quality of life study group. Acta Oncol. 1994;33:879-85.

10. Aaronson NK, Ahmedzai S, Bergman B, Bullinger M, Cull A, Duez NJ, Filiberti A, Flechtner H, Fleishman SB, de Haes JC. The European Organization for Research and Treatment of Cancer QLQ-C30: a quality-of-life instrument for use in international clinical trials in oncology. J Natl Cancer Inst. 1993;85:365-76.

11. Bjordal K, de Graeff A, Fayers PM, Hammerlid E, van Pottelsberghe C, Curran D, Ahlner-Elmqvist M, Maher EJ, Meyza JW, Brédart A, Söderholm AL, Arraras JJ, Feine JS, Abendstein H, Morton RP, Pignon T, Huguenin P, Bottomly A, Kaasa S. A 12 country field study of the EORTC QLQ-C30 (version 3.0) and the head and neck cancer specific module (EORTC QLQ-H\&N35) in head and neck patients. EORTC quality of life group. Eur J Cancer. 2000;36:1796-807.

12. Bjordal K, Kaasa S. Psychometric validation of the EORTC Core quality of life questionnaire, 30-item version and a diagnosis-specific module for head and neck cancer patients. Acta Oncol. 1992;31:311-21.

13. Kyrgidis A, Triaridis S, Kontos K, Patrikidou A, Andreadis C, Constantinidis J, Vahtsevanos K, Antoniades K. Quality of life in breast cancer patients with bisphosphonate-related osteonecrosis of the jaws and patients with head and neck cancer: a comparative study using the EORTC QLQ-C30 and QLQHN35 questionnaires. Anticancer Res. 2012;32:3527-34.

14. Chie WC, Hong RL, Lai CC, Ting LL, Hsu MM. Quality of life in patients of nasopharyngeal carcinoma: validation of the Taiwan Chinese version of the EORTC QLQ-C30 and the EORTC QLQ-H\&N35. Qual Life Res. 2003;12:93-8.

15. Mazzola RF, Lupo G. Evolving concepts in lip reconstruction. Clin Plast Surg. 1994;11:583-617.

\section{Publisher's Note}

Springer Nature remains neutral with regard to jurisdictional claims in published maps and institutional affiliations.

\section{Ready to submit your research? Choose BMC and benefit from:}

- fast, convenient online submission

- thorough peer review by experienced researchers in your field

- rapid publication on acceptance

- support for research data, including large and complex data types

- gold Open Access which fosters wider collaboration and increased citations

- maximum visibility for your research: over $100 \mathrm{M}$ website views per year

At BMC, research is always in progress.

Learn more biomedcentral.com/submissions 